\title{
A Novel Effect of Lipids Extracted from Vernix Caseosa on Regulation of Filaggrin Expression in Human Epidermal Keratinocytes
}

\author{
Wu Qiao, Tinghan Jia ${ }^{1}$, Hongjian $\mathrm{Gu}^{1}$, Ruihua Guo, Ken $\mathrm{Kaku}^{1}$, Wenhui Wu \\ Department of Marine Bio-Pharmacology, College of Food Science and Technology, Shanghai Ocean University, ${ }^{1}$ Pigeon Maternal E Infant \\ Skin Care Research Institute, Shanghai, China
}

Background: Vernix caseosa (VC), which is known as a unique human substance, is a biofilm that covers the skin of most human newborns. VC has many biological functions including anti-infective, skin cleansing and skin barrier repair. Objective: In the study, we purpose to investigate the novel effect of lipids extracted from VC on the regulation of filaggrin (FLG) expression and anti-inflammation in normal human epidermal keratinocyte (NHEK) cells. Methods: The lipids were extracted by chloroform/methanol (Folch method) and the major properties of fatty acid methyl esters were determined with gas chromatography-mass spectrometer. The relative viability of NHEK cells was evaluated by Cell Counting Kit 8 assay. The related expression of skin barrier protein was accessed with real-time quantitative polymerase chain reaction, Western blot and Immunofluorescence in NHEK cells with or without poly (I:C). Meanwhile, the changes of thymic stromal lymphopoietin (TSLP) and tumor necrosis factor alpha (TNF- $\alpha$ ) are analyzed by enzyme-linked immunosorbent assay. Results: VC lipids mostly contained saturated and branched chains fatty acids. The expression of mRNA and protein of FLG were significantly

Received May 17, 2019, Revised July 23, 2019, Accepted for publication August 21, 2019

Corresponding author: Tinghan Jia, Pigeon Maternal \& Infant Skin Care Research Institute, Wenhui Wu, Shanghai Hucheng Ring Road 999, Shanghai 201306, China. Tel: 86-021-6922-5686, Fax: 86-021-6922-5686, E-mail: adolf@pigeon.cn

ORCID: https://orcid.org/0000-0002-2852-7571

This is an Open Access article distributed under the terms of the Creative Commons Attribution Non-Commercial License (http://creativecommons. org/licenses/by-nc/4.0) which permits unrestricted non-commercial use, distribution, and reproduction in any medium, provided the original work is properly cited.

Copyright (c) The Korean Dermatological Association and The Korean Society for Investigative Dermatology increased after the supplement with lipid in NHEK cells. Meanwhile, lipids reversed the inhibition of poly (I:C) on FLG. Moreover, lipids suppressed the over secretion of TSLP and TNF- $\alpha$ induced by poly (I:C). Conclusion: These results indicate that lipids extracted from $\mathrm{VC}$ has positive effects on the expression of FLG and anti-inflammation, suggesting that lipids of VC may be used for a reference for novel therapeutic method in reducing and remedying skin disease like atopic disease. (Ann Dermatol 31(6) 611 620, 2019)

\section{-Keywords-}

Fatty acids, Inflammation, Keratinocytes, Vernix caseosa

\section{INTRODUCTION}

Atopic dermatitis (AD), which has approximately affected $25 \%$ of children and $3 \%$ of adults in the word, is a common, chronic and perennial skin inflammatory allergic disease. More seriously, the life quality of infant, children and teenagers with AD has been seriously destroyed ${ }^{1}$. The main cause of AD contains genetic defects and exogenous factor stimulation. Genetic study has proved the significance of filament aggregation protein (filaggrin, FLG) gene in $\mathrm{AD}$ patient skin ${ }^{2}$. The FLG, which assembles and aggregates keratin to form the keratin-matrix-complex that is an outer lipid envelope as an efficient barrier to prevention of water loss, mechanical damage, microorganism invasion $^{3}$, is a significant ingredient in stratum corneum (SC) which is important structure of the skin. Recent studies have showed that FLG null mutations play a key role in the pathogenesis of AD and FLG defect is aggravated by the imbalance of T helper 2 (Th2) cytokine in AD patients $^{4,5}$. Polyinosine-polyribocytidylic acid (poly I:C), a 
common synthetic double-stranded RNA (dsRNA), can stimulate toll-like receptor-3 (TLR-3) to activate B cells and dendritic cells to secret pro-inflammatory cytokine that can bring out immune responses in AD patient ${ }^{6,7}$.

Vernix caseosa (VC), a white and cheesy biofilm, covers the SC of the skin of newborn when fetus go through the pregnancy stage of the last three months ${ }^{8}$. VC is a multifunctional skin cream, which participates in multiple physiological regulation. In utero, VC works as an effective waterproof film, protects the baby from harmful substance existed in amniotic fluid and takes part in the development of gastrointestinal and skin epidermis ${ }^{9}$. After baby birth, VC can maintains low skin $\mathrm{pH}$ and significantly improves skin hydration. Bautista has found that adult forearm skin inside improved the capacity of moisture-binding after the treatment with $\mathrm{VC}^{10}$. Besides, VC-based creams are beneficial material to treat epidermal wounds, SC maturation and repair ${ }^{11}$.

The main ingredient of VC contains $80.5 \%$ water, $10.3 \%$ protein and $9.1 \%$ lipids in natural environment ${ }^{12}$. Lipids are critical matrix for the barrier of the VC and nonpolar lipids are major component of the VC lipids. Sterol esters and triglycerides constitute main part of individual lipids, which are made up of straight long chain fatty acids and diverse methyl branched fatty acids ${ }^{13}$. VC as a natural topical agent has similar structure with SC and the pioneer information of VC has been obtained. The lipids compositions of SC mainly contain free fatty acids, which compared with VC is interesting. It has been found that a lot of fatty acids that were from phospholipids can regulates the levels of SC acidification and improve SC integrity ${ }^{14}$ and their 1-monoacylglycerols have antibacterial activity in vitro ${ }^{15}$. Boiten et al. ${ }^{16}$ and Tollin et al. ${ }^{17}$ applied a ceramide mixture based on the ingredient of the VC to facilitate SC barrier development. The anti-inflammatory effect of some fatty acids has been founded in many situations ${ }^{18,19}$.

However, the effects of lipids extracted from VC on the normal human epidermal keratinocyte (NHEK) cells, especially on the structural protein FLG, had not been investigated. The objective of this study is to explore fatty acids composition of VC lipids and access its novel effects on the FLG and anti-inflammation in vitro.

\section{MATERIALS AND METHODS}

\section{Sample collecting}

VC was immediately gathered from six male and four female newborn subjects who were provided at full term condition (weeks of gestation reached $40 \sim 42$ weeks). VC samples were put in glass sample bottles and stored under $-80^{\circ} \mathrm{C}$ condition. Blood-polluted samples were abandon- ed. The study was approved by the Ethics Committees of the Shanghai Clinical Research Center (IRB no. C181108) and with the 1964 Helsinki declaration and its later amendments or comparable ethical standards. This article does not contain any studies with animals performed by any of the authors. We received the patient's consent form about publishing all photographic materials.

\section{Lipids extraction}

Lipids extracted from vernix were obtained using the Folch method that is previously described ${ }^{20}$. Briefly, $1 \mathrm{~g}$ clean VC was added $20 \mathrm{ml}$ of chloroform/methanol mixture (ratio of mixture: 2/1, V/V). After vortex for 15 $20 \mathrm{mi}$ nutes and centrifugation at $1,500 \mathrm{rpm}$ for $1 \mathrm{~min}$ at room temperature, the liquids phase is collected. The solvent is washed with 0.2 volume of water. After centrifugation at $2,000 \mathrm{rpm}$ for $10 \mathrm{~min}$ and discarding the supernatant, methanol and water were added in proportion of 1:1 volume ratio to the liquid phase. Finally, the lower level chloroform phase was dries with $\mathrm{N}_{2}$ and samples were stored in $-80^{\circ} \mathrm{C}$ condition until using.

\section{Cell culture}

NHEK cells were purchased from Guangdong Biocell Co., Ltd. (Guangdong, China) and cultured in Epilife medium (Gibco; Thermo Fisher Scientific, Waltham, MA, USA) with $60 \mu \mathrm{M} \mathrm{Ca}^{2+}$ and human keratinocyte growth supplement (HKGS; Gibco) in a humidified at the condition of atmosphere of $95 \%$ air and $5 \% \mathrm{CO}_{2}$ at $37^{\circ} \mathrm{C}$. The Epilife medium was changed every two days until the cells were used for the next experiment at $75 \%$ to $85 \%$ confluence. The cells were grown for no more than 8 cell generations.

\section{Cell viability assay}

The NHEK cells were seeded into 96-well plates (Nunc; Thermo Fisher Scientific) at a density $4 \times 10^{3}$ cells/well. Then cells were incubated in serum-free culture medium for 12 hours. Cells were exposed to lipids and poly $(\mathrm{I}: \mathrm{C})$ $(0 \sim 400 \mu \mathrm{g} / \mathrm{ml})$ (Sigma-Aldrich, St. Louis, MO, USA) for 24 hours. After adding Cell Counting Kit 8 (CCK-8; Beyotime Biotechnology, Shanghai, China) $10 \mu \mathrm{l} / 100 \mu \mathrm{l}$, cell viability was accessed by reading absorbance at 450 nm (ID5 Plate Reader; Molecular Device, San Jose, CA, USA). According the results of the cells viability (\%), suitable poly $(\mathrm{I}: \mathrm{C})$ and lipids concentrations were chosen. The calculation formula of viability is as follows:

Viability $(\%)=\left(O D_{\text {treatment group }}-\mathrm{OD}_{\text {blank background }}\right) /$

$\mathrm{OD}_{\text {control group }} \times 100 \%$

\section{Lipids supplement and inflammatory stimulation}

NHEK cells $\left(2 \times 10^{4}\right.$ cells/ml) were seeded into 6-well 
plates (Nunc). NHEK cells were maintained in Epilife medium containing $1.3 \mu \mathrm{M} \mathrm{Ca}^{2+}$ and HKGS. After culturing for 72 hours, the medium was changed to fresh Epilife medium containing different concentrations of lipids (25 $\mu \mathrm{g}$ / $\mathrm{ml}, 50 \mu \mathrm{g} / \mathrm{ml}$ and $100 \mu \mathrm{g} / \mathrm{ml}$ ) that is according to the results of cell viability assays for extra 24 hours. For inflammatory stimulation, NHEK cells were cultured in Epilife medium with HKGS and $1.5 \mu \mathrm{M} \mathrm{Ca}^{2+}$ for 72 hours and adding poly (I:C) $(10 \mu \mathrm{g} / \mathrm{ml})$ to medium to stimulate for 24 hours, different concentrations of lipids (25, 50, and 100 $\mu \mathrm{g} / \mathrm{ml})$ were added medium for extra 24 hours.

\section{Real-time quantitative polymerase chain reaction analysis}

The treated cells were lysis with the TRIZOL reagent (Invitrogen Technologies, Carlsbad, CA, USA) following the manufacturer's recommended protocol. The content and quality of total RNA were measured by Qubit 3.0 (Thermo Fisher Scientific). This target RNA fragment was chosen as a basic template for subsequent cDNA synthesis using the Prime script RT reagent Kit (Thermo Fisher Scientific). To measure related mRNA levels, SYBR Premix Ex Taq II (Takara Bio Inc., Dalian, China) were performed using the Light Cycler 96 system (Roche, Basel, Switzerland) following the manufacturer's recommended protocol and primers were listed in Table 1 . The data were analyzed using the delta cycle threshold method and $2^{-\Delta \Delta \mathrm{CT}}$ method, and the expression levels of each gene were normalized to glyceraldehyde 3-phosphate dehydrogenase (GAPDH). All values are reported as means \pm standard deviation (SD).

\section{Western blotting}

The NHEK cells were risen with pre-cold phosphate-buffered saline $(\mathrm{pH} 7.4)$ to inhibit protease activity. Total soluble protein extracted using M-PER Mammalian Protein Extraction Reagent (Thermo Fisher Scientific) with a protease inhibitor mixture (1:100; Roche Applied Science, Basel, Switzerland). The protein concentration was measured by a bicinchoninic acid (Pierce; Thermo Fisher Scientific) kit according to the instructions. The $12 \%$ sodium dodecyl sulphate-polyacrylamide gel electrophoresis was used to separated total proteins (20 $\mu \mathrm{g})$, then gel was transferred onto a polyvinylidene fluoride (PVDF) membrane using iBlot 2 system (Thermo Fisher Scientific). The PVDF membrane was blocked with $5 \%$ bovine serum albumin (BSA) for 1 hour. After blocking, the PVDF membrane was incubated in $0.1 \%$ Tris buffered saline with Tween 20 including primary antibody anti-FLG (1:2,000; Thermo Fisher Scientific), anti-GAPDH (1:3000; Invitrogen Technologies) overnight at $4^{\circ} \mathrm{C}$. Next, the membrane was washed and incubated with horseradish peroxidase-conjugated secondary antibody (1:15,000; Abcam, Cambridge, UK) for 1 hour. Protein expression was detected using iBright L1000 image system (Thermo Fisher Scientific). The results of protein expression were quantified with densitometry normalized to GAPDH by iBright analysis software (Thermo Fisher Scientific).

\section{Immunofluorescence assay}

After treatment, the treated cells were added $4 \%$ paraformaldehyde to fix cells for 30 minutes at room temperature. After fixation, cells were incubated in $0.05 \%$ Triton X-100 for 30 minutes to permeate cell. Then, the cells were blocked with $5 \%$ BSA buffer and incubated with primary FLG antibody (1:500; Abcam) overnight at $4{ }^{\circ} \mathrm{C}$. The cells were treated with an Alexflour 488-conjugated secondary Goat anti-rabbit IgG (1:100; Invitrogen Technologies) for 2 hours in the dark conditions. The nuclei were dyed by incubation with 4',6-diamidino-2-phenylindole (1:1,000 dilution; Thermo Fisher Scientific) for 20 minutes at room temperature. The results of cells were observed with EVOS FL autoll fluorescence microscope (Life Technology, Boston, MA, USA) and analyzed using the EVOS browser imaging software.

\section{Measurement of secreted thymic stromal lymphopoietin and interleukin-1 $\alpha$ by enzyme-linked immunosorbent assay}

After poly (I:C)-stimulated NHEK cells were treated with different concentrations of lipid for 24 hours, the samples were collected from the cell supernatants. Tumor necrosis factor alpha (TNF- $\alpha$ ), thymic stromal lymphopoietin (TSLP) were determined by enzyme-linked immunosorbent assay

Table 1. Primer designed for real-time quantitative PCR

\begin{tabular}{lll}
\hline Gene name & \multicolumn{1}{c}{ Forward } & Revise \\
\hline FLG & GCAAGGTCAAGTCCAGGAGA & CCCTCGGTTTCCACTGTCTC \\
TSLP & ACTCTCGACTTGTGTTCCCC & TGGCGAACATTTCTTTGGCG \\
TNF- $\alpha$ & TATCCTGGGGGACCCAATGT & AGCTTCTTCCCACCCACAAG \\
GAPDH & CGGAGTCAACGGATTTGGTCGTAT & AGCCTTCTCCATGGTGGTGAAGAC \\
\hline
\end{tabular}

PCR: polymerase chain reaction, FLG: filaggrin, TSLP: thymic stromal lymphopoietin, TNF- $\alpha$ : tumor necrosis factor alpha, GAPDH: glyceraldehyde 3-phosphate dehydrogenase. 
(ELISA) kits in triplicate (R\&D Systems, Minneapolis, MN, USA). The tests were strictly carried out according to the manufacturer's protocols.

\section{Gas chromatography-mass spectrometer of fatty acid methyl esters}

The lipids extracted from VC were converted into fatty acid methyl esters by incubation in $10 \%$ vitriol $\left(\mathrm{H}_{2} \mathrm{SO}_{4}\right)$ /methanol for 3 hours at $70^{\circ} \mathrm{C}$. After adding $2 \mathrm{ml} \mathrm{n}$-hexane (Sigma-Aldrich), $1 \mathrm{ml}$ of ultrapure water was added to aid stratification, and the supernatant was aspirated for detection. The methyl esters were analyzed by gas chromatography-mass spectrometer (GC-MS; Agilent 7890B; Agilent Technologies, CA, USA) containing a 5977 MSD connected with a HP-5MS (5\% phenyl, polymethyl siloxane column) $(30 \mathrm{~m} \times 250 \mathrm{~mm} \times 0.25 \mu \mathrm{m})$. A $1 \mu \mathrm{l}$ specimen was injected into the GC inlet with a syringe. The split ratio was set as $1: 20$ and the temperature of inlet was kept at $250^{\circ} \mathrm{C}$. Initial column temperature was $100^{\circ} \mathrm{C}$, rising at a rate of $2^{\circ} \mathrm{C} / \mathrm{min}$, holding $180^{\circ} \mathrm{C}$ for 2 minutes, then rising at a rate of $2^{\circ} \mathrm{C} / \mathrm{min}, 220^{\circ} \mathrm{C}$ holding 3 minutes, at last rising to $290^{\circ} \mathrm{C}$ at a rate of $5^{\circ} \mathrm{C} / \mathrm{min}$, maintaining for 2 minutes. The carrier gas, helium, utilized at a flow rate of $1.0 \mathrm{ml} / \mathrm{min}$. Mass charge ratio scanning was performed from 50 to $500 \mathrm{~m} / \mathrm{z}$ with electron ionization $(70 \mathrm{eV})$. The area of each peak under the curve was automatic integration and the relative percentage was obtained compared with integrated using ChemStation software. Database similarities (\%) higher than 85 was considered acceptably for correct identification.

\section{Statistical analyses}

All the values have been reported in terms of means $\pm S D$. The mean values were calculated based on data from at least three independent replicate experiments. The data were analyzed using the Student's t-test. $p$-value less than 0.05 was considered statistically significant. All statistical analyses were performed using SPSS ver. 22.0 (IBM Corp., Armonk, NY, USA).

\section{RESULTS}

\section{Cytotoxicity of lipids and poly (I:C) in NHEK cells}

The CCK-8 assay was used to evaluate the safety of lipids and poly (I:C). As is shown in Fig. 1, NHEK cells were exposed to different concentration of lipids extracted from VC and poly (I:C; 400, 200, 100, 50, 25, 12.5, 6.25, $0 \mu \mathrm{g} /$ $\mathrm{ml}$ ) and cell vitality was decreased in a dose-dependent manner. Cells cytotoxicity induced by lipids was significantly increased at concentrations greater than $100 \mu \mathrm{g} /$ $\mathrm{ml}$. So, we used $100 \mu \mathrm{g} / \mathrm{ml}, 50 \mu \mathrm{g} / \mathrm{ml}, 25 \mu \mathrm{g} / \mathrm{ml}$ as the safe concentration of lipids. Poly (I:C), as an inflammatory stimulator, a dose-dependent decreased cell vitality also has been found (Fig. 1B). When NHEK cells were exposed to $25 \mu \mathrm{g} / \mathrm{ml}$ poly (I:C), the cell vitality was significantly decreased. When the concentration of poly (I:C) was greater than $50 \mu \mathrm{g} / \mathrm{ml}$, the cell vitality kept a low level. Thus, we choose $10 \mu \mathrm{g} / \mathrm{ml}$ poly (I:C) as a suitable concentration for further experiments.
A

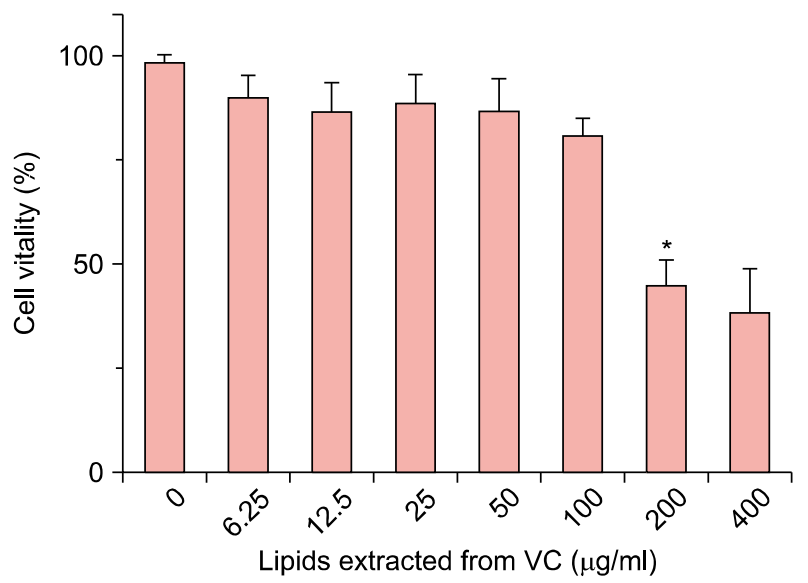

B

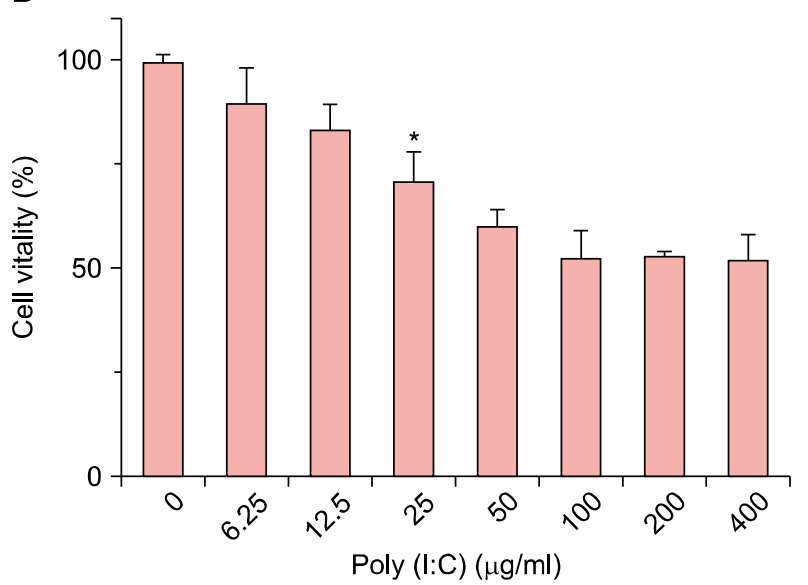

Fig. 1. The effect of lipids extracted from vernix caseosa (VC) and Poly (I:C) on normal human epidermal keratinocyte (NHEK) cells viability. (A) NHEK cells were exposed on lipids at the different concentrations (400, 200, 100, 50, 25, 12.5, 6.25, $0 \mu \mathrm{g} / \mathrm{ml})$ for 24 hours. (B) NHEK cells were exposed on poly (I:C) at the different concentrations $(400,200,100,50,25,12.5,6.25,0 \mu \mathrm{g} / \mathrm{ml})$ for 24 hours. Cell viability was assessed by Cell Counting Kit 8 assay. The results are representative of five independent experiments. Bars means standard deviations. ${ }^{*} p<0.05$. 


\section{The effect of lipids on the expression of FLG gene and protein expression}

Real-time quantitative polymerase chain reaction (RT-qPCR) and western blot were used to measure the changes of FLG protein expression induced by lipids with or without poly $(\mathrm{I}: \mathrm{C})$ in vitro. In the NHEK cells, stimulation with lipids at 25,50, $100 \mu \mathrm{g} / \mathrm{ml}$ for 24 hours increased the expression of FLG, which were less than positive control (15 uM WY14643). Fig. 2A presented that the $50 \mu \mathrm{g} / \mathrm{ml}$ lipids group significantly $(p<0.01)$ increased the FLG mRNA level compared with poly (I:C)-untreated control group. Meanwhile, the protein expression of FLG was significantly increased than normal control group (Fig. 2B). In Fig. 2A, there is a clear decreasing trend of gene expression of FLG in poly (I:C)-treated group compared with poly (I:C)-untreated. The addition of lipids with 25, 50, $100 \mu \mathrm{g} / \mathrm{ml}$ effectively reversed inhibition of poly (I:C) on FLG gene expression (Fig. 2A). Fig. 2C showed that $50 \mu \mathrm{g} /$ $\mathrm{ml}$ lipids significantly improved FLG expression compared with normal control and poly (I:C)-treated group. The re- sult of immunofluorescence $50 \mu \mathrm{g} / \mathrm{ml}$ lipids significantly $(p<0.01)$ increased the FLG protein expression under normal condition in vivo. Meanwhile, the addition of poly (I:C) significantly decreased FLG expression $(p<0.05)$. Further, the FLG protein expression significantly improved after the treatment of $50 \mu \mathrm{g} / \mathrm{ml}$ lipids for 24 hours (Fig. 3).

\section{Lipid suppress the secretion of TNF- $\alpha$ and TSLP in NHEK}

NHEK cells were treated with $10 \mu \mathrm{g} / \mathrm{ml}$ ploy (I:C) to induce the inflammatory response and simultaneously exposed to lipids at various concentrations. TNF- $\alpha$ and TSLP are important in the development of inflammatory response, which were measured by RT-qPCR (Fig. 4A) and ELISA (Fig. 4B) in NHEK cells. The levels of TNF- $\alpha$ and TSLP was significantly increased when NHEK cells were exposed to $10 \mu \mathrm{g} / \mathrm{ml}$ poly (I:C) for 24 hours (Fig. 4). But treatment with $25 \mu \mathrm{g} / \mathrm{ml}, 50 \mu \mathrm{g} / \mathrm{ml}$, and $100 \mu \mathrm{g} / \mathrm{ml}$ lipids significantly decreased the mRNA level of TNF- $\alpha$ and TSLP (Fig. 4A). Further, the results of ELISA illustrated that the protein level of TNF- $\alpha$ and TSLP significantly reduced after the treatment with $50 \mu \mathrm{g} / \mathrm{ml}, 100 \mu \mathrm{g} / \mathrm{ml}$ lipids com-
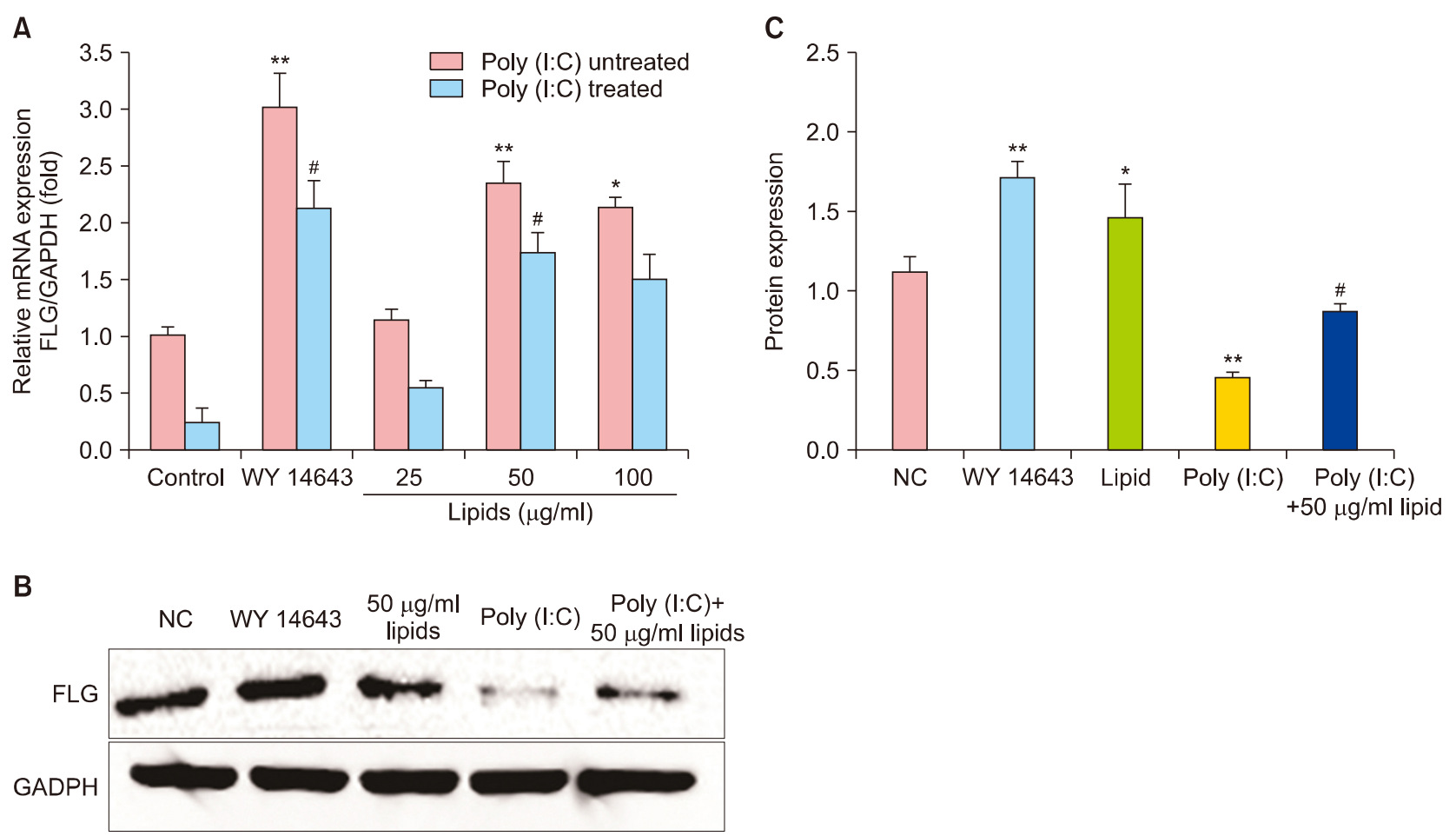

Fig. 2. The positive effect of lipids on filaggrin (FLG) mRNA and protein in normal human epidermal keratinocyte cells. (A) The levels of FLG mRNA increased after treatment with positive control (WY14643) and different lipids under poly (I:C) untreated and poly $(\mathrm{I}: \mathrm{C})$ treated condition; real-time quantitative polymerase chain reaction. (B) The FLG protein expression increased after treatment with positive control (WY14643) and lipids; Western blot. (C) Quantitative processing of FLG protein expression. Data are presented in graphical form that shows the fold change compared with control group and relative density. The values are the mean \pm standard deviation of at least three independent experiments in duplicate. GAPDH: glyceraldehyde 3-phosphate dehydrogenase, NC: normal control. ${ }^{*} p<0.05$ compared with normal control, ${ }^{* *} p<0.01,{ }^{\sharp} p<0.05$ compared with poly (I:C)-treated group. 

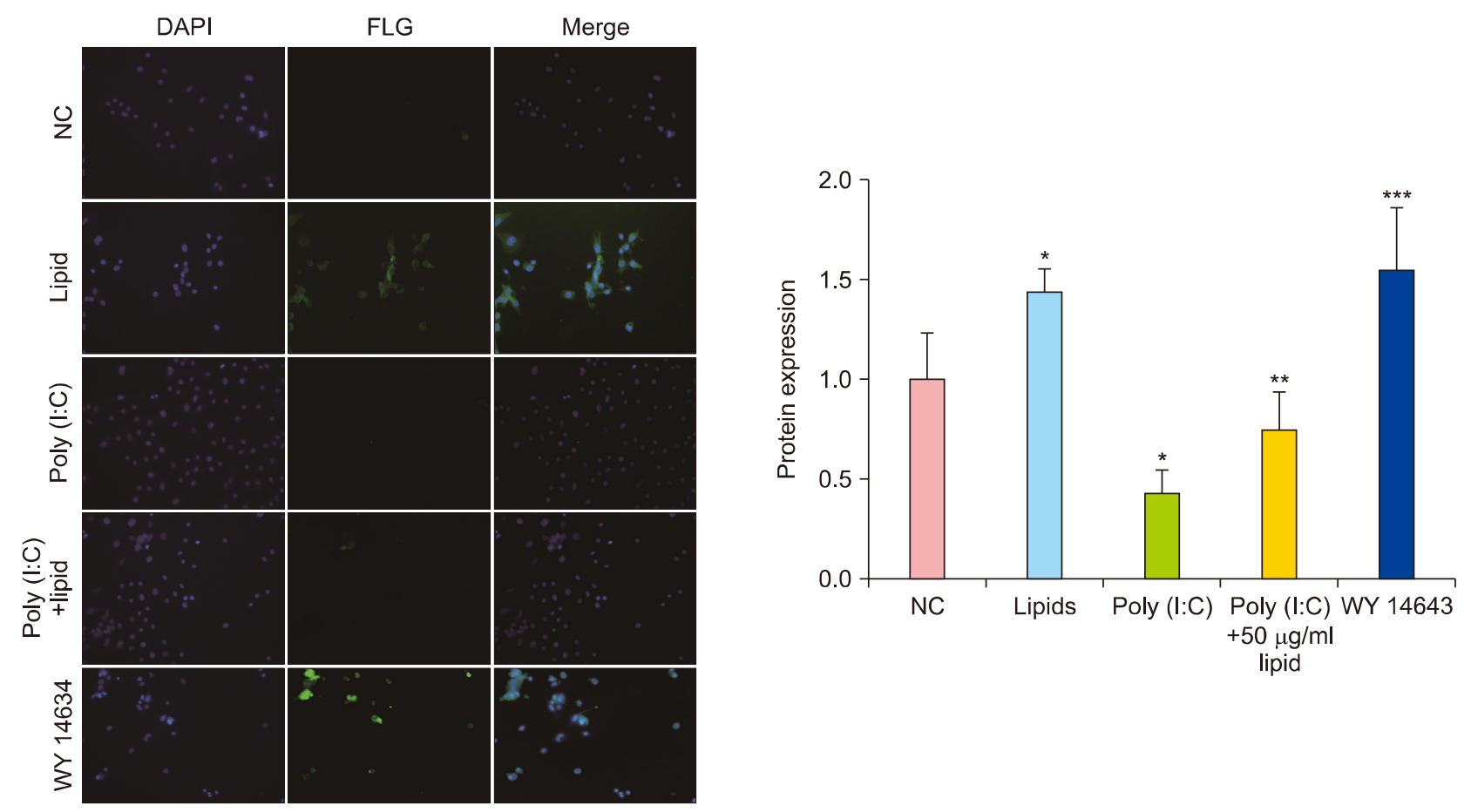

Fig. 3. Lipids improved the expression of filaggrin (FLG) with or without poly (I:C) in normal human epidermal keratinocytes; immunofluorescence $\times 200$. The data are expressed as relative density in graphical form (FLG/glyceraldehyde 3-phosphate dehydrogenase [GADPH]). Bars mean standard deviations. DAPI: $4{ }^{\prime}, 6$-diamidino-2-phenylindole. ${ }^{*} p<0.05$ compared with normal control, ${ }^{* *} p<0.05$ compared with poly (I:C)-treated group, $* * * p<0.01$.

pared with poly (I:C)-treated group $(p<0.01)$ (Fig. 4B). These results suggest that lipids extracted from VC could negatively control the inflammatory responses by suppressing TNF- $\alpha$ and TSLP.

\section{The composition of VC fatty acids}

As in shown in Table 2, the composition of fatty acid methyl esters (FAME) was analysis by GC-MS. The high contribution originated from 14:0, 16:0, 16:1, 18:0, and $18: 1$. These contributed more than $10 \%$ to the total fatty acids in our samples. The major methylated fatty acids constituents of lipid were methyl tetradecanoate (49.83\%), Tetradecanoic acid (8.2\%), hexadecanoic acid, methyl ester $(7.29 \%)$, Methyl stearate $(2.27 \%)$, etc. Other minor methylated fatty acid compounds were detected in the vernix extract including tridecanoic acid, methyl ester $(0.11 \%)$, pentadecanoic acid, methyl ester $(0.23 \%)$, 9-hexadecenoic acid, methyl ester $(0.21 \%)$, 9,12-octadecadienoic acid methyl ester $(0.26 \%)$, methyl 9-(Z)-octadecenoate $(0.95 \%)$. Some other fat-soluble alkanes compounds were also determined. However, some branched methylated fatty acids were detected included tridecanoic acid, 12-methyl-, methyl ester $(0.92 \%)$, tetradecanoic acid, 12-methyl-, methyl ester $(1.31 \%)$, methyl(Z)-hexadec-9-enoate $(0.28 \%)$, methyl -hexadecanoic acid-methyl ester (0.24\%).

\section{DISCUSSION}

The proFLG presented in stratum granulosum is degraded to generate FLG that is a critical role for the integrity of the SC and calcium is involved in the procession of proFLG degradation during terminal epidermal differentiation ${ }^{21}$. Finally, FLG is degraded to produce its partial component amino acids, a mixture of hygroscopic amino acids, called natural moisturizing factor that is contributed to SC acidification and hydration $^{22}$. It has been founded that the skin presents the degressive expression of FLG in patients with $\mathrm{AD}^{23}$. So, FLG deficiency has a key role in pathogenesis of $A D$, which improves the risk of microbial infection and has an impact on the integrity of the epidermis. There are many novel therapeutic approaches to treat $A D$ or other atopic diseases by adjusting FLG expression.

VC is a noteworthy biofilm that covers the skin of most human fetus and newborns. Because the increasing impacts in water-holding capacity, skin inflammation and immunity, VC that contains abundant lipids have been studied in many fields. High internal phase water-in-oil emulsions designed as VC analogues have better semi-permeability and water-handling properties than conventional lipids, which is closed to native vernix ${ }^{24}$. Vernix caseosa mimetic, another vernix analogue, can improve the skin 
A

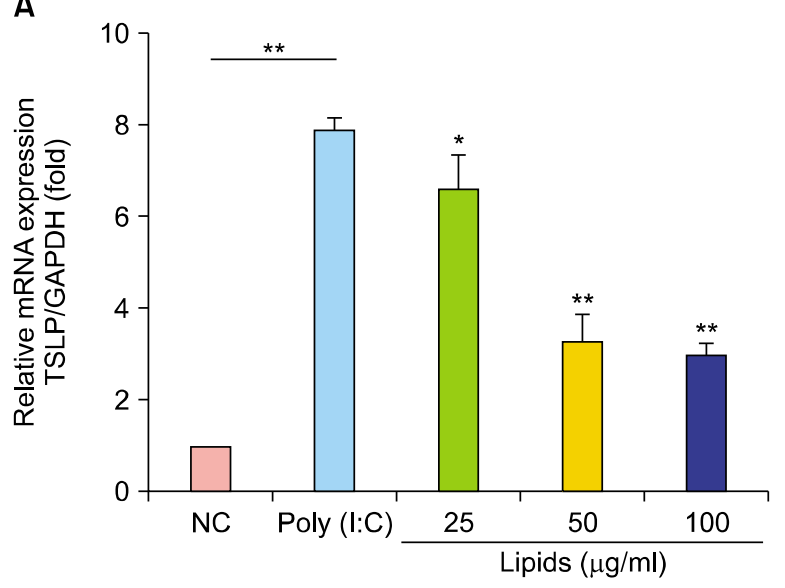

B

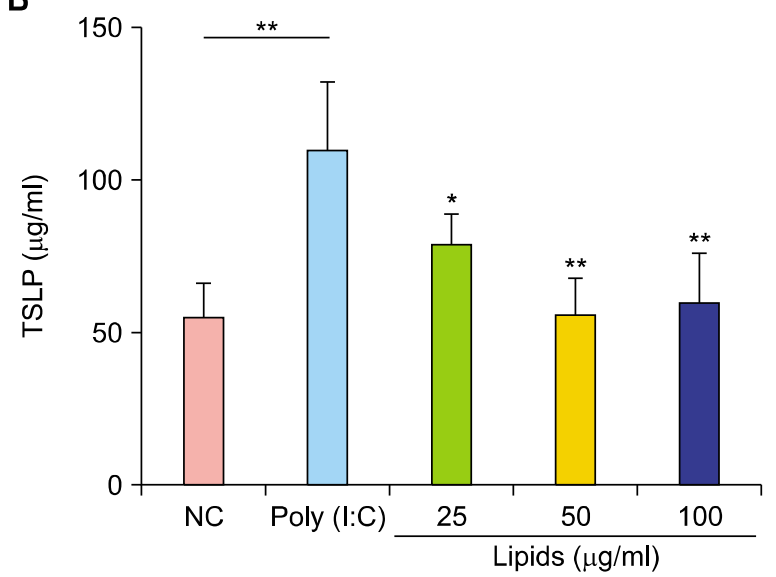

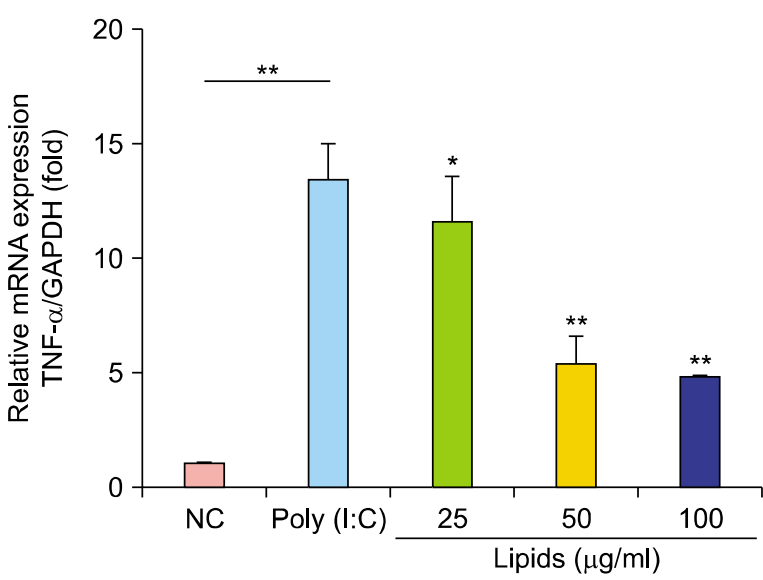

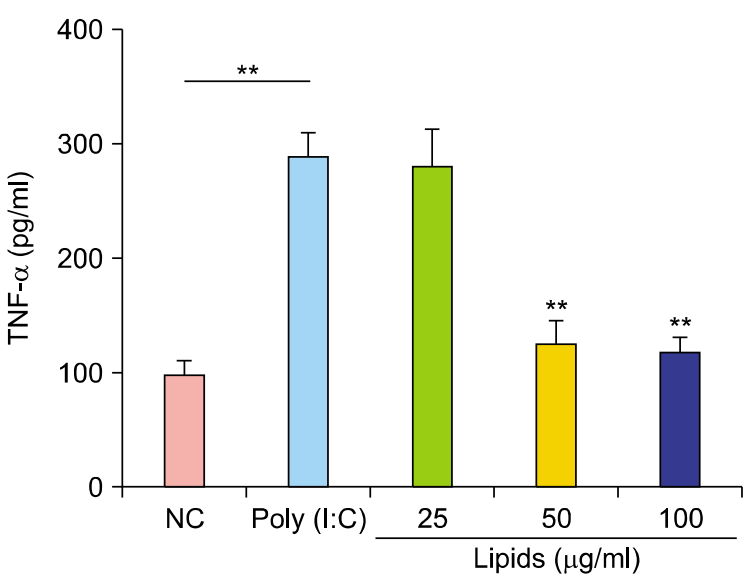

Fig. 4. (A) mRNA levels of thymic stromal lymphopoietin (TSLP) and tumor necrosis factor alpha (TNF- $\alpha$ ) induced by poly (I:C) decreased after treatment with different concentration lipid in normal human epidermal keratinocyte (NHEK) cells; real-time quantitative polymerase chain reaction. (B) The protein levels of TSLP and TNF- $\alpha$ induced by poly (I:C) decreased after treatment with lipid in NHEK cells; enzyme-linked immunosorbent assay. The values are the mean \pm standard deviation of at least three independent experiments in duplicate. GAPDH: glyceraldehyde 3-phosphate dehydrogenase. ${ }^{*} p<0.05,{ }^{* *} p<0.01$.

barrier repair and increase the capacity of SC moisturization $^{25}$. Further, some studies indicated that there are some differences of lipid compositions in lesion and AD skin compared with health $\mathrm{skin}^{26}$, which is related to levels and chain length of fatty acids. Besides, the changes of lipid composition and organization had been investigated in human skin SC after topical treatment with free acids ${ }^{27}$. Previous studies have showed that palmitoleic acid (C16:1) and linoleic acid (C18:2) have powerful antimicrobial and antiviral activity and unsaturated fatty acids can upgrade the expression of $\mathrm{FLG}^{28}$. In our study, FAME species mainly contains saturated, monounsaturated (C14:0, C16:0 and C16:1, C18:1) and branched fatty acids (Table 2), which is well line with recent report ${ }^{29}$. But, there is no study to investigate whether lipids extracted from VC have an impact on FLG in vitro. We first quantified effects in mRNA and protein expression of FLG in NHEK cells treat- ed with different concentrations of lipids (Fig. 2). Our study showed that the lipids extracted from VC can increase the expression of gene and protein expression of FLG in NHEK cells.

Epidermal keratinocytes play a central role in immune reaction and inflammatory ${ }^{30}$, in which dsRNA brings out a series of responses. TSLP, an interleukin (IL)-17-like cytokine, is overexpressed by keratinocytes in lesion skin with $A D^{31}$, which has a downregulatory effect on FLG by signal transducer and activator of transcription 3 and extracellular signal-regulated kinase-depend pathways ${ }^{32}$. Howell et al. ${ }^{33}$ has reported that Th2 cytokines can improve viral replication by downregulation of the secretion of LL-3 in the lesion skin with AD, which indicated that Th2 and poly I:C synergistically stimulate the release of TSLP. Rouaud-Tinguely et al. ${ }^{34}$ had demonstrated that IL-4 and IL-13 can down-regulate the expression of FLG and 
Table 2. Fatty acid methyl esters

\begin{tabular}{rrllc}
\hline No. & Time & Molecular & \multicolumn{1}{c}{ Name } & Area (\%) \\
\hline 1 & 2.76 & $\mathrm{C}_{10} \mathrm{H}_{22}$ & Decane & 0.50 \\
2 & 3.04 & $\mathrm{C}_{12} \mathrm{H}_{26}$ & Dodecane & 2.44 \\
3 & 6.05 & $\mathrm{C}_{20} \mathrm{H}_{42}$ & Eicosane & 1.96 \\
4 & 7.00 & $\mathrm{C}_{21} \mathrm{H}_{44}$ & Heneicosane & 2.37 \\
5 & 7.46 & $\mathrm{C}_{28} \mathrm{H}_{58}$ & Octacosane & 0.43 \\
6 & 9.11 & $\mathrm{C}_{14} \mathrm{H}_{28} \mathrm{O}_{2}$ & Tridecanoic acid, methyl ester & 0.11 \\
7 & 9.42 & $\mathrm{C}_{13} \mathrm{H}_{10} \mathrm{O}$ & Benzophenone & 0.15 \\
8 & 10.61 & $\mathrm{C}_{16} \mathrm{H}_{34} \mathrm{O}$ & 2-hexyl-1-Decanol & 0.12 \\
9 & 10.99 & $\mathrm{C}_{15} \mathrm{H}_{30} \mathrm{O}_{2}$ & Tridecanoic acid, 12-methyl-, methyl ester & 0.92 \\
10 & 12.27 & $\mathrm{C}_{15} \mathrm{H}_{30} \mathrm{O}_{2}$ & Methyl tetradecanoate & 49.83 \\
11 & 13.53 & $\mathrm{C}_{14} \mathrm{H}_{28} \mathrm{O}_{2}$ & Tetradecanoic acid & 8.20 \\
12 & 14.39 & $\mathrm{C}_{16} \mathrm{H}_{32} \mathrm{O}_{2}$ & Tetradecanoic acid,12-methyl-methyl ester & 1.31 \\
13 & 15.76 & $\mathrm{C}_{16} \mathrm{H}_{32} \mathrm{O}_{2}$ & Pentadecanoic acid, methyl ester & 0.23 \\
14 & 17.22 & $\mathrm{C}_{17} \mathrm{H}_{32} \mathrm{O}_{2}$ & 9-Hexadecenoic acid, methyl ester & 0.21 \\
15 & 18.20 & $\mathrm{C}_{17} \mathrm{H}_{34} \mathrm{O}_{2}$ & Hexadecanoic acid, methyl ester & 0.91 \\
16 & 18.79 & $\mathrm{C}_{17} \mathrm{H}_{32} \mathrm{O}_{2}$ & Methyl(Z)-hexadec-9-enoate & 0.28 \\
17 & 19.68 & $\mathrm{C}_{17} \mathrm{H}_{34} \mathrm{O}_{2}$ & Hexadecanoic acid, methyl ester & 7.29 \\
18 & 21.07 & $\mathrm{C}_{16} \mathrm{H}_{32} \mathrm{O}_{2}$ & n-Hexadecanoic acid & 0.38 \\
19 & 22.81 & $\mathrm{C}_{18} \mathrm{H}_{36} \mathrm{O}_{2}$ & methyl -Hexadecanoic acid-methyl ester & 0.24 \\
20 & 27.67 & $\mathrm{C}_{19} \mathrm{H}_{34} \mathrm{O}_{2}$ & 9,12-Octadecadienoic acid methyl ester & 0.26 \\
21 & 28.05 & $\mathrm{C}_{19} \mathrm{H}_{36} \mathrm{O}_{2}$ & Methyl 9-(Z)-octadecenoate & 0.95 \\
22 & 29.64 & $\mathrm{C}_{19} \mathrm{H}_{38} \mathrm{O}_{2}$ & Methyl stearate & 2.27 \\
23 & 77.46 & $\mathrm{C}_{27} \mathrm{H}_{46} \mathrm{O}$ & Cholesterol & 0.26 \\
\hline
\end{tabular}

the over-expression of the Th2 was showed up in acute AD skin. The activation of TSLP will have an negative impact on innate immunity and trigger a nuclear transcription factor $(\kappa \mathrm{B})^{35}$. In this study, poly I:C mimicked viral dsRNA to stimulate the massive expression of TSLP (Fig. 4). Meanwhile, our study demonstrated that lipids significantly inhibits the production of TSLP induced by poly (I:C) in NHEK cells. Interestingly, previous studies observed that self-dsRNA from damaged skin can trigger the production of TSLP by TLR-3 pathway, which has been founded as a potential mechanism for inhibition of inflammation $^{36}$. We speculate that lipids extracted from VC can interfere the TLR-3 pathway to decrease the production of TSLP responses induced by dsRNA. We also demonstrated that lipid significantly decrease the impact of poly (I:C) on FLG genes in vivo (Fig. 3). Additionally, poly $(\mathrm{I}: \mathrm{C})$ also stimulates normal NHEKs to release pro-inflammatory cytokines that will in turn stimulate other related cells to produce various adhesion molecules and cytokines such as IL-1 and IL-8, which can accrue inflammatory cells to lead inflammatory reaction. Our study showed that TNF- $\alpha$ significantly increased induced by 10 $\mathrm{ug} / \mathrm{ml}$ poly (I:C). In recent study, TNF- $\alpha$ alone or combined with Th2 cytokines can affect barrier lipid properties and cause the reduction in the distribution of free fatty acids $^{37}$. In our study, the mRNA and protein levels of TNF- $\alpha$ significantly decreased after the treatment of different concentration of lipids.

There are some limitations in this study. First, which components of lipids increase the mRNA and protein expression of the FLG has not been investigated. Furthermore, the mechanism for inducing the inhibition of poly (I:C) on FLG is not known. So, additional experiments are going on to handle these limitations.

In conclusion, our findings indicate that VC lipids have some beneficial effects on improving skin barrier function through increasing expression of FLG and regulating the NHEK cells inflammation by inhibiting the secretion of TSLP and TNF- $\alpha$. Therefore, lipids extracted from VC may be used for a reference for novel therapeutic method in reducing and remedying skin disease like atopic disease.

\section{CONFLICTS OF INTEREST}

The authors have nothing to disclose.

\section{ORCID}

Wu Qiao, https://orcid.org/0000-0003-0782-4478

Tinghan Jia, https://orcid.org/0000-0002-2852-7571

Hongjian Gu, https://orcid.org/0000-0002-7800-2431

Ruihua Guo, https://orcid.org/0000-0001-8414-886X 
Ken Kaku, https://orcid.org/0000-0003-0258-2078

Wenhui Wu, https://orcid.org/0000-0002-1710-8582

\section{REFERENCES}

1. Yamazaki Y, Nakamura $Y$, Núñez G. Role of the microbiota in skin immunity and atopic dermatitis. Allergol Int 2017; 66:539-544.

2. Palmer $C N$, Irvine $A D$, Terron-Kwiatkowski $A$, Zhao $Y$, Liao $\mathrm{H}$, Lee SP, et al. Common loss-of-function variants of the epidermal barrier protein filaggrin are a major predisposing factor for atopic dermatitis. Nat Genet 2006;38:441-446.

3. Brown SJ, McLean WH. One remarkable molecule: filaggrin. J Invest Dermatol 2012;132(3 Pt 2):751-762.

4. Irvine $A D, M c L e a n W H$, Leung DY. Filaggrin mutations associated with skin and allergic diseases. N Engl J Med 2011;365:1315-1327.

5. Brandt EB, Sivaprasad U. Th2 cytokines and atopic dermatitis. J Clin Cell Immunol 2011;2:110.

6. Brown JN, Kohler JJ, Coberley CR, Sleasman JW, Goodenow MM. HIV-1 activates macrophages independent of Toll-like receptors. PLoS One 2008;3:e3664.

7. Sutmuller RP, Morgan ME, Netea MG, Grauer O, Adema $G$. Toll-like receptors on regulatory $T$ cells: expanding immune regulation. Trends Immunol 2006;27:387-393.

8. Hoath SB, Pickens WL, Visscher MO. The biology of vernix caseosa. Int J Cosmet Sci 2006;28:319-333.

9. Tansirikongkol A, Wickett RR, Visscher MO, Hoath SB. Effect of vernix caseosa on the penetration of chymotryptic enzyme: potential role in epidermal barrier development. Pediatr Res 2007;62:49-53.

10. Bautista MI, Wickett RR, Visscher MO, Pickens WL, Hoath SB. Characterization of vernix caseosa as a natural biofilm: comparison to standard oil-based ointments. Pediatr Dermatol 2000;17:253-260.

11. Visscher MO, Barai N, LaRuffa AA, Pickens WL, Narendran $\mathrm{V}$, Hoath SB. Epidermal barrier treatments based on vernix caseosa. Skin Pharmacol Physiol 2011;24:322-329.

12. Yan $Y$, Wang $Z$, Wang $D$, Lawrence $P$, Wang $X$, Kothapalli $K S D$, et al. BCFA-enriched vernix-monoacylglycerol reduces LPS-induced inflammatory markers in human enterocytes in vitro. Pediatr Res 2018;83:874-879.

13. Fu HC, Nicolaides $\mathrm{N}$. The structure of alkane diols of diesters in vernix caseosa lipids. Lipids 1969;4:170-175.

14. Fluhr JW, Kao J, Jain M, Ahn SK, Feingold KR, Elias PM. Generation of free fatty acids from phospholipids regulates stratum corneum acidification and integrity. J Invest Dermatol. 2001;117:44-51.

15. Bergsson G, Arnfinnsson J, Steingrímsson O, Thormar $\mathbf{H}$. Killing of Gram-positive cocci by fatty acids and monoglycerides. APMIS 2001;109:670-678.

16. Boiten WA, Berkers T, Absalah S, van Smeden J, Lavrijsen APM, Bouwstra JA. Applying a vernix caseosa based formulation accelerates skin barrier repair by modulating lipid biosynthesis. J Lipid Res 2018;59:250-260.

17. Tollin M, Bergsson G, Kai-Larsen Y, Lengqvist J, Sjövall J,
Griffiths W, et al. Vernix caseosa as a multi-component defence system based on polypeptides, lipids and their interactions. Cell Mol Life Sci 2005;62:2390-2399.

18. Bergsson G, Arnfinnsson J, Karlsson SM, Steingrímsson O, Thormar $\mathrm{H}$. In vitro inactivation of Chlamydia trachomatis by fatty acids and monoglycerides. Antimicrob Agents Chemother 1998;42:2290-2294.

19. Wille JJ, Kydonieus A. Palmitoleic acid isomer (C16:1delta6) in human skin sebum is effective against gram-positive bacteria. Skin Pharmacol Appl Skin Physiol 2003;16:176187.

20. Folch J, Lees M, Sloane Stanley GH. A simple method for the isolation and purification of total lipides from animal tissues. J Biol Chem 1957;226:497-509.

21. Sandilands A, Sutherland C, Irvine AD, McLean WH. Filaggrin in the frontline: role in skin barrier function and disease. J Cell Sci 2009;122(Pt 9):1285-1294.

22. Choi SY, Kim MJ, Ahn GR, Park KY, Lee M-K, Seo SJ. The effect of adiponectin on the regulation of filaggrin expression in normal human epidermal keratinocytes. Ann Dermatol 2018;30:645-652.

23. Seguchi T, Cui CY, Kusuda S, Takahashi M, Aisu K, Tezuka T. Decreased expression of filaggrin in atopic skin. Arch Dermatol Res 1996;288:442-426.

24. Tansirikongkol A, Visscher MO, Wickett RR. Water-handling properties of vernix caseosa and a synthetic analogue. J Cosmet Sci 2007;58:651-662.

25. Lee MS, Yoo YK, Lee KK. Preparation and characterization of vernix caseosa analogues. Kor J Aesthet Cosmetol 2014; 12:547-553.

26. Agrawal R, Woodfolk JA. Skin barrier defects in atopic dermatitis. Curr Allergy Asthma Rep 2014;14:433.

27. Berkers T, van Dijk L, Absalah S, van Smeden J, Bouwstra JA. Topically applied fatty acids are elongated before incorporation in the stratum corneum lipid matrix in compromised skin. Exp Dermatol 2017;26:36-43.

28. Wallmeyer L, Lehnen D, Eger N, Sochorová M, Opálka L, Kováčik $A$, et al. Stimulation of PPARa normalizes the skin lipid ratio and improves the skin barrier of normal and filaggrin deficient reconstructed skin. J Dermatol Sci 2015; 80:102-110.

29. Liu YJ. Thymic stromal lymphopoietin: master switch for allergic inflammation. J Exp Med 2006;203:269-273.

30. Míková R, Vrkoslav V, Hanus R, Háková E, Hábová Z, Doležal $\mathrm{A}$, et al. Newborn boys and girls differ in the lipid composition of vernix caseosa. PLoS One 2014;9:e99173.

31. Kim JH, Bae HC, Ko NY, Lee $\mathrm{SH}$, Jeong $\mathrm{SH}$, Lee $\mathrm{H}$, et al. Thymic stromal lymphopoietin downregulates filaggrin expression by signal transducer and activator of transcription 3 (STAT3) and extracellular signal-regulated kinase (ERK) phosphorylation in keratinocytes. J Allergy Clin Immunol 2015;136:205-208.e209.

32. Miller LS, Modlin RL. Human keratinocyte Toll-like receptors promote distinct immune responses. J Invest Dermatol 2007; 127:262-263.

33. Howell MD, Gallo RL, Boguniewicz M, Jones JF, Wong C, Streib JE, et al. Cytokine milieu of atopic dermatitis skin 
subverts the innate immune response to vaccinia virus. Immunity 2006;24:341-348.

34. Rouaud-Tinguely P, Boudier D, Marchand L, Barruche V, Bordes $\mathrm{S}$, Coppin $\mathrm{H}$, et al. From the morphological to the transcriptomic characterization of a compromised threedimensional in vitro model mimicking atopic dermatitis. $\mathrm{Br}$ J Dermatol 2015;173:1006-1014.

35. Dumortier A, Durham AD, Di Piazza M, Vauclair S, Koch $U$, Ferrand $G$, et al. Atopic dermatitis-like disease and associated lethal myeloproliferative disorder arise from loss of Notch signaling in the murine skin. PLoS One 2010;5: e9258.

36. Lai Y, Di Nardo A, Nakatsuji T, Leichtle A, Yang Y, Cogen $\mathrm{AL}$, et al. Commensal bacteria regulate Toll-like receptor 3-dependent inflammation after skin injury. Nat Med 2009; 15:1377-1382.

37. Danso MO, van Drongelen V, Mulder A, van Esch J, Scott $\mathrm{H}$, van Smeden J, et al. TNF- $\mathrm{a}$ and Th2 cytokines induce atopic dermatitis-like features on epidermal differentiation proteins and stratum corneum lipids in human skin equivalents. J Invest Dermatol 2014;134:1941-1950. 